\title{
Self-Assembled Silane Film and Silver Nanoparticles Coating on Magnesium Alloys for Corrosion Resistance and Antibacterial Applications
}

Rongchang ZENG ${ }^{1) \dagger}$, Lijun $L I U^{1)}$, Shuoqi $L I^{1) \dagger}$, Yuhong ZOU ${ }^{2)}$, Fen ZHANG ${ }^{1)}$, Yanan YANG ${ }^{2)}$, Hongzhi $C U I^{1)}$ and En-hou $H A N^{3)}$

1) College of Material Science and Engineering, Shandong University of Science and Technology, Qingdao 266590, China

2) College of Chemical and Environmental Engineering, Shandong University of Science and Technology, Qingdao 266590, China

3) State Key laboratory for Corrosion and Protection, Institute of Metals Research, Chinese Academy of Sciences, Shenyang 110016, China

[Manuscript received 13 July 2013, in revised form 24 August 2013]

(C) The Chinese Society for Metals and Springer-Verlag Berlin Heidelberg

\begin{abstract}
Contamination resulting from microbial adhesion on magnesium alloys is very common in many applications. Self-assembly technology was employed to prepare an antibacterial composite coating by fixing silver nanoparticles (AgNPs) onto the surface of magnesium alloys. The AgNPs were immobilized on the surface of 3-aminopropyltrimethoxysilane (APTMS)-modified magnesium alloy AZ31 (APTMS/Mg) through electrostatic inter-attraction between partially protonated amino groups and negatively charged citrate-capped AgNPs, resulting in the AgNPs attached APTMS/Mg (AgNPs/APTMS/Mg) substrate. The prepared Ag colloid and functionalized AZ31 alloy were characterized by ultraviolet-visible (UV-vis) spectroscopy, Fourier transform infrared (FTIR) spectroscopy, scanning electron microscopy (SEM), and electrochemical methods. Finally, the bactericidal activity of AgNPs/APTMS/Mg substrate against Escherichia coli was assessed by the inhibition zone. The results demonstrated that $\mathrm{Si}-\mathrm{O}-\mathrm{Si}$ covalent bonds existed on the substrate with the formation of inorganic Si-O-Mg bonds. AgNPs were immobilized and well-dispersed, forming a uniform submonolayer on the silane film in two dimensions. The AgNPs/APTMS-pretreated AZ31 alloys exhibited better corrosion resistance and excellent antibacterial performance.
\end{abstract}

KEY WORDS: Magnesium alloy; Nanoparticles; Self-assembly; Corrosion; Antibacterial effect

\section{Introduction}

The use of magnesium alloys as degradable metals for biomedical applications is a topic of ongoing research and the demand for multifunctional materials increases $^{[1]}$. For example, contamination resulting from microbial adhesion on magnesium alloys is very common in many applications, and therefore, antibacterial performance is required under these applications ${ }^{[2,3]}$. At the same time, magnesium alloys are also prone to corrosion in aggressive

\footnotetext{
† Corresponding author. Ph.D.; Tel.: +86 532 80681226; E-mail address: lishuoqi@sdust.edu.cn (Shuoqi LI)

Prof., Ph.D.; Tel.: +86 532 80681226; E-mall address: rczeng@forxmail.com (Rongchang ZENG)
}

environments $^{[4-9]}$. Thus, the demand of high functionality of magnesium alloy with antibacterial functions as well as corrosion resistance effects has been increasing.

The expected multifunctionality can be achieved by self-assembly of monolayers and nanoparticles. Self-assembled monolayers (SAMs) are ordered molecular assemblies formed by chemisorptions of an active surfactant on a solid surface ${ }^{[10,11]}$. In the selfassembly method, functionalized organic thin films can be spontaneously formed on the oxide layer of $\mathrm{Mg}$ substrates by immersion into the solution of silanes ${ }^{[12]}$. The obtained silane layer acquires anticorrosive properties ${ }^{[13]}$. The terminal organo-functional groups determine the exposed silane monolayer surface functionality, which open the possibility for 
further functionality of the surface of magnesium alloys $^{[14-16]}$.

Many researchers who applied the self-assembly technology to surface chemistry focused on AgNPs because of their interesting antibacterial $\operatorname{activities}^{[17-19]}$. And the manner in which these nanoparticles assemble was determined by capping materials surrounding AgNPs. One of the most common capping materials is citrate, which encourages the dispersion of AgNPs and imparts negative charges to the particles. Negatively charged AgNPs in aqueous media are often assembled onto the positively charged primary aminoterminated surface of the substrates by electrostatic interaction ${ }^{[20]}$. Thus, $-\mathrm{NH}_{2}$ terminated 3aminopropyltrime-thoxysilane (APTMS) often provides a possibility to deposit AgNPs onto the substrate.

In this work, the self-assembly method for immobilizing AgNPs onto Mg alloy AZ31 surface by using the linking agent APTMS was introduced. The APTMS was deposited on the substrate as a functional monolayer. Through this method, fixed AgNPs/APTMS/Mg substrate with obvious anticorrosive properties was obtained, and the bactericidal efficiency against Escherichia coli was so notable that it would appear to provide a possibility of multifunctionality and have an enormous potential in health care.

\section{Experiment}

\subsection{Materials and chemicals}

The used materials are an as-extruded $\mathrm{Mg}$ alloy AZ31 with a normal chemical composition (wt.\%): Al 2.5-3.0, $\mathrm{Zn} 0.7-1.3, \mathrm{Mn}>0.20$ and $\mathrm{Mg}$ is balanced. APTMS with $97 \%$ purity was purchased from Alfa Aesar. $\mathrm{AgNO}_{3}, \mathrm{NaBH}_{4}, \mathrm{NaCl}$ and $\mathrm{C}_{6} \mathrm{H}_{5} \mathrm{Na}_{3} \mathrm{O}_{7} \cdot 2 \mathrm{H}_{2} \mathrm{O}$ were of analytical reagent grade, and double distilled water was used throughout. All the measurements were performed at room temperature.

\subsection{Preparation of AgNPs}

The solution of $4 \mathrm{~nm} \mathrm{Ag}$ colloid was prepared by the procedure reported by Jana et al. ${ }^{[21]}$. That is, $0.6 \mathrm{~mL} 0.01 \mathrm{~mol} / \mathrm{L} \mathrm{NaBH}_{4}$ solution was added to $20 \mathrm{~mL}$ solution which containing $0.5 \mathrm{~mL} 0.01 \mathrm{~mol} / \mathrm{L}$ $\mathrm{AgNO}_{3}$ and $0.5 \mathrm{~mL} 0.01 \mathrm{~mol} / \mathrm{L}$ trisodium citrate, and the mixture was maintained for $2 \mathrm{~h}$ with stirring. The obtained yellow Ag colloid was used within $2 \mathrm{~d}$. The $\mathrm{pH}$ value of the $\mathrm{Ag}$ colloid was adjusted by $\mathrm{HCl}$ and $\mathrm{NaOH}$ solutions from 5.94 to 4.05 and 7.68 , respectively.

\subsection{Self-assembly of AgNPs on AZ31 surface}

The surfaces of the AZ31 alloy specimen with size of $10 \mathrm{~mm} \times 10 \mathrm{~mm} \times 7.5 \mathrm{~mm}$ were prepared with sand papers up to 1500 grade, washed with distilled wa- ter to remove excess impurities. AZ31 coupons were then alkaline aged in $0.1 \mathrm{~mol} / \mathrm{L} \mathrm{NaOH}$ for $24 \mathrm{~h}$ at room temperature, rinsed in distilled water and dried in natural air. The hydroxide layer on AZ31 surface is expected to promote surface condensation of APTMS.

The specimens were then immersed in silanic solutions $(0.1 \mathrm{vol} . \%)$ for $24 \mathrm{~h}$. In the presence of water, the organosilane molecules $\left(\mathrm{H}_{2} \mathrm{~N}-\left(\mathrm{CH}_{2}\right)_{3}\right.$-Si$\left.\left(\mathrm{OCH}_{3}\right)_{3}\right)$ quickly hydrolyze into trihydroxyl intermediate products $\left(\mathrm{H}_{2} \mathrm{~N}-\left(\mathrm{CH}_{2}\right)_{3}-\mathrm{Si}-(\mathrm{OH})_{3}\right)$, which have a high tendency to crosslink with one another to build a network structure (Si-O-Si), with the formation of SAMs at the liquid-solid interface $(\mathrm{Si}-\mathrm{O}-\mathrm{Mg})^{[22]}$. After that, specimens (APTMS/Mg) were rinsed in distilled water and dried in natural air.

To immobilize the AgNPs, the APTMS/Mg was immersed in the Ag colloid. AgNPs could be immobilized onto the APTMS/Mg substrate through electrostatic inter-attraction between protonated amino groups and negatively charged citrate-capped AgNPs. After $24 \mathrm{~h}$, the substrate was taken out, washed with distilled water and dried with natural air. Fig. 1 outlines the idealized pictures of the proposed methodology schematically.

\subsection{Characterization}

UV-vis spectrum of the Ag colloid solution was measured by UV-vis spectrophotometer TU-1901 (Purkinje General, China). SEM observations were carried out by a scanning electron microscope (S4800 Hitachi, Japan). The possible chemical bonding formed in the composite was characterized by FTIR spectrometry Nicolet 380 (Thermo Electron Corporation, USA). Potentiodynamic polarization curves were performed by an electrochemical analyzer (PAR Model 2273, Princeton, USA) in a three-electrode system with the sample as working electrode, saturated calomel electrode as reference electrode and platinum sheet as counter electrode. The experiment was carried out in a corrosive environment of $3.5 \mathrm{wt} . \%$ $\mathrm{NaCl}$ solution at room temperature. The polarization started from about $-2000 \mathrm{mV}$ to $-1000 \mathrm{mV}$ at a scan rate of $2 \mathrm{mV} / \mathrm{s}$. A quantity of Escherichia coli suspension $\left(10^{-5}-10^{-4} \mathrm{CFU} / \mathrm{mL}\right)$ was uniformly spread over the agar plates. Mg, APTMS/Mg and AgNPs/APTMS/Mg substrates were carefully placed at the center of the agar plates ${ }^{[23]}$.

\section{Results and Discussion}

\subsection{SEM images of AgNPs/APTMS/Mg substrate}

The SEM images were adopted to characterize the AgNPs assembled on the Mg AZ31 surfaces. The surface density of AgNPs was estimated by calculating the AgNPs amount in three different analysis areas $(1 \mu \mathrm{m} \times 1 \mu \mathrm{m})$. It is observed that, for AgNPs/APTMS/Mg sample, a highly dispersed and uniform monolayer was formed and the surface density 


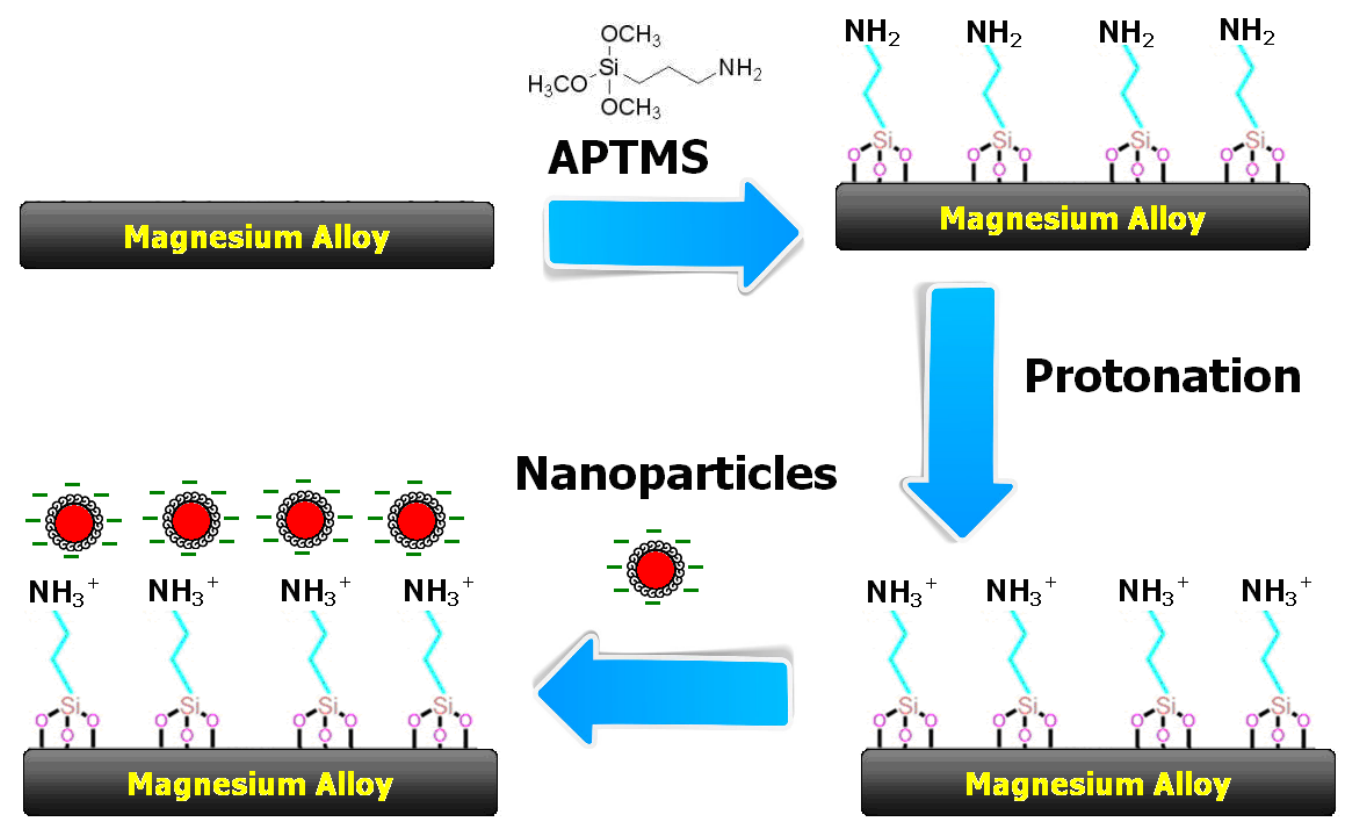

Fig. 1 Schematic of the APTMS modification process and AgNPs attachment onto the APTMS/Mg surface

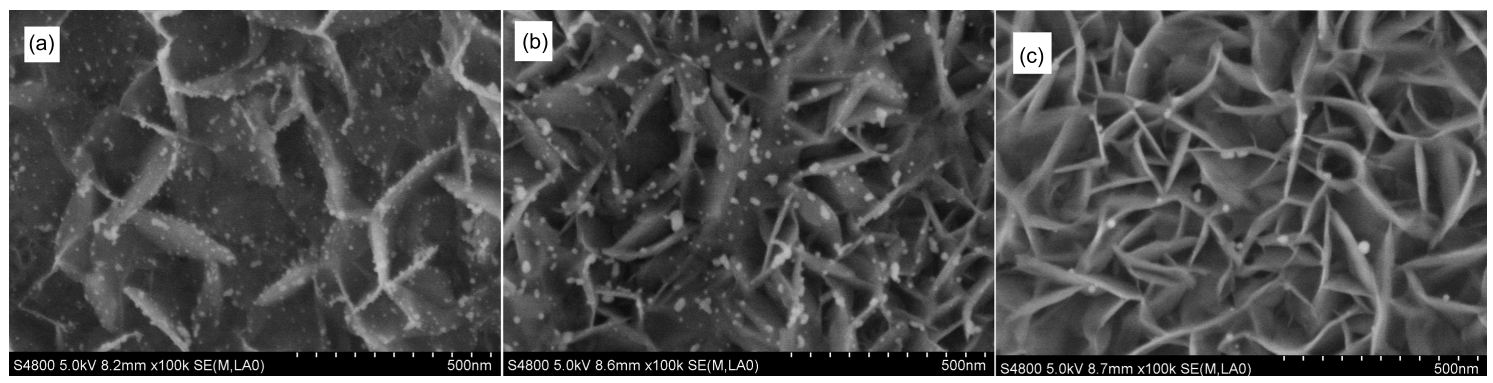

Fig. 2 SEM images of AgNPs/APTMS/Mg surfaces prepared in different Ag colloidal solutions with pH values of 5.94 (a), 4.05 (b) and 7.68 (c) after $24 \mathrm{~h}$ assembly (white dots indicate AgNPs)

of AgNPs was about $550 \mu \mathrm{m}^{-2}$ (Fig. 2(a)). This result confirmed the importance of APTMS to attach AgNPs.

The $\mathrm{pH}$ dependence of AgNPs adsorption on APTMS/Mg was examined in the $\mathrm{pH}$ value range from 4.05 to $7.68^{[24]}$. As observed in the SEM images, there is a significant aggregation of AgNPs at $\mathrm{pH}$ value of 4.05 (Fig. 2(b)), and the surface density of AgNPs is $250 \mu \mathrm{m}^{-2}$. The aggregated structure can be ascribed to the fact that, as the $\mathrm{pH}$ value deceases, the citrate capped onto the AgNPs would be protonated and AgNPs would be less negatively charged, which leads to the weakening of inter-repulsion between adjacent AgNPs and aggregation occurred. The best, well dispersed, and uniform layer has formed at $\mathrm{pH}$ value of 5.94 (Fig. 2(a)) while almost no adsorption was found at $\mathrm{pH}$ value of 7.68 (Fig. 2(c)). This can be ascribed to the fact that the nature of the bond between the AgNPs, and the amino groups are the electrostatic attraction. The amino groups are positively charged and can interact strongly with the negatively charged AgNPs surface. As the $\mathrm{pH}$ increases, the protonation of the amino groups decreases, and finally protonation stops; thus, no further electrostatic attraction occurs. As a result, the immobilization of AgNPs was almost inhibited at $\mathrm{pH}$ value of 7.68. Thus, the $\mathrm{pH}$ value as an adjustable parameter, is very important in controlling the surface density and the dispersity of AgNPs onto APTMS/Mg surfaces ${ }^{[24]}$.

\subsection{UV-vis absorption spectra}

UV-vis absorption spectrum is proven to be sensitive to the formation of Ag colloid. The width of absorbance peak is qualitatively dependent on the particle size distribution, while its height is related to the concentration of $\mathrm{AgNPS}_{\mathrm{S}}{ }^{25]}$. The UV-vis spectrum (Fig. 3) shows the narrow band absorption centered at a wavelength of $411 \mathrm{~nm}$ and reveals a uniform size and stable nature without aggregation of AgNPs.

\subsection{FTIR spectra of APTMS/Mg}

The existence of silane molecules on APTMS/Mg 


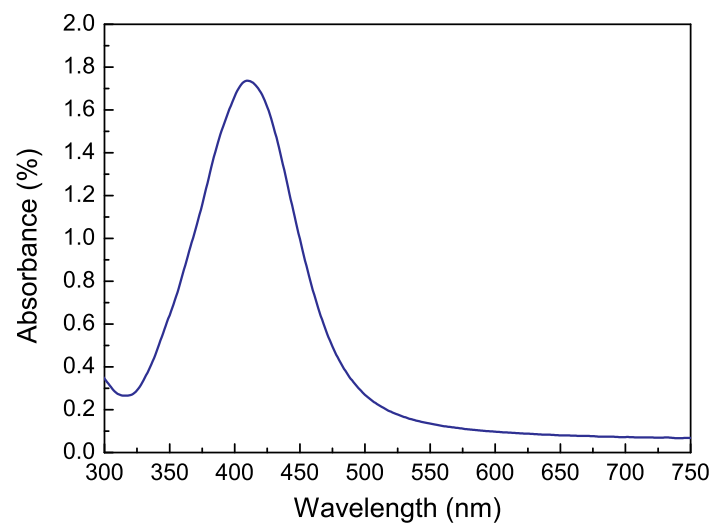

Fig. 3 UV-vis spectrum of Ag colloid

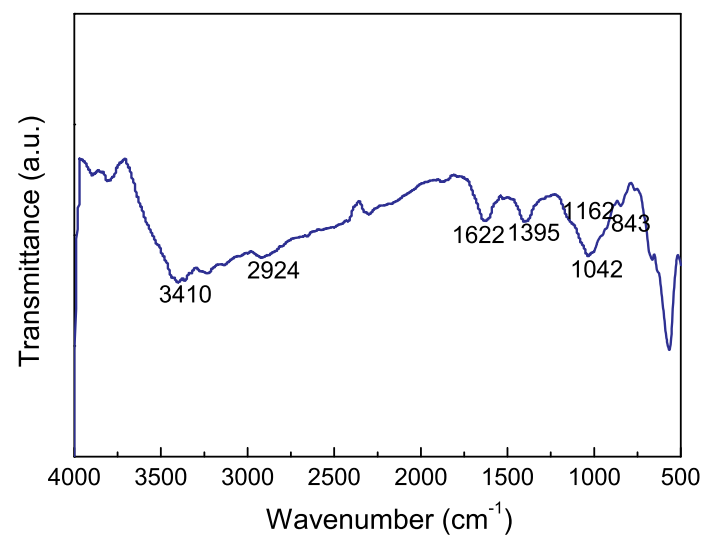

Fig. 4 FTIR spectrum of APTMS/Mg sample

substrate can be verified by the FTIR spectra as shown in Fig. 4. The peak at near $3410 \mathrm{~cm}^{-1}$ was attributed to the O-H stretching vibration of Si-OH resulting from the hydrolyzation of silane groups ${ }^{[13,26]}$. Peaks near $2924 \mathrm{~cm}^{-1}$ and $1395 \mathrm{~cm}^{-1}$ were attributed to symmetric and asymmetric stretching of $\mathrm{CH}_{2}^{[22]}$ and $\mathrm{CH}_{2}$ alkyl chain bend ${ }^{[27]}$, respectively. The $\mathrm{N}$ $\mathrm{H}$ bending vibration of primary amines was observed at $1622 \mathrm{~cm}^{-1}$ and another low intensity peak at $1162 \mathrm{~cm}^{-1}$ was assigned to $\mathrm{C}-\mathrm{N}$ bond ${ }^{[28]}$. The peak corresponding $\mathrm{Si}-\mathrm{O}$ asymmetric stretching in Si-O$\mathrm{Si}$ and $\mathrm{Mg}-\mathrm{O}-\mathrm{Si}$ was observed at round $1042 \mathrm{~cm}^{-1}$. And the $\mathrm{Si}-\mathrm{C}$ bond stretched at $843 \mathrm{~cm}^{-1[29]}$. These peaks demonstrated the formation of inorganic $\mathrm{Mg}$ O-Si bonds at the substrate surface ${ }^{[30]}$ with the crosslinking between silanol groups ${ }^{[31]}$.

\subsection{Potentiodynamic polarization measurements}

In order to determine the effectiveness of APTMS and AgNPs/APTMS coatings on corrosion resistance, potentiodynamic measurements were conducted in 3.5 wt. $\% \mathrm{NaCl}$ solutions at room temperature ${ }^{[32]}$. The corrosion current density, $i_{\text {corr }}$ was determined by Tafel extrapolation method. The changes of free corrosion potentials, $E_{\text {corr }}$ can be used to estimate the corrosion resistance of metals and $i_{\text {corr }}$ indicates the

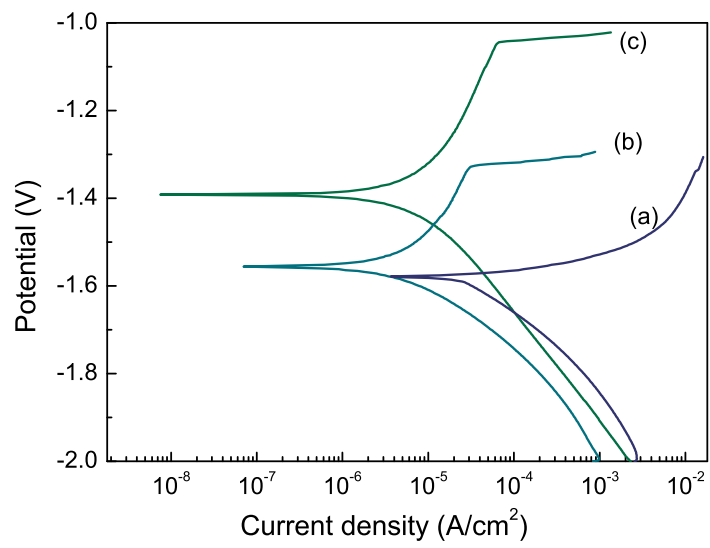

Fig. 5 Potentiodynamic polarization curves of $\mathrm{Mg}$ (a), APTMS/Mg (b) and AgNPs/APTMS/Mg (c)

corrosion rates theoretically ${ }^{[33]}$. For good corrosion resistance, the result should be low current density and high potential voltage, generally ${ }^{[34,35]}$.

Representative potentiodynamic polarization curves obtained from the un-coated and coated AZ31 magnesium samples are displayed in Fig. 5 and the relevant electrochemical parameters were listed in Table 1 . The $E_{\text {corr }}$ of the un-coated alloy is quite negative and only about $-1580 \mathrm{mV}$. Compared with the substrate AZ31, $E_{\text {corr }}$ for coated samples b and c were shifted positively $30 \mathrm{mV}$ and $190 \mathrm{mV}$, respectively. It is also noted that the $i_{\text {corr }}$ of the coated alloy was decreased approximately by one order of the magnitude after the modification by APTMS, suggesting a much lower corrosion rate for the coated alloy compared to that of the un-coated specimen ${ }^{[36,37]}$. The potentiodynamic polarization test reveals that the corrosion resistance of the coated alloy is improved significantly ${ }^{[38]}$.

Besides, Corrosion behavior of the with respect to the breakdown potential $\left(E_{\mathrm{b}}\right)$ by potentiodynamic polarization tests was also investigated. $E_{\mathrm{b}}$ represents the potential at which the current starts to rise significantly indicating the film breakdown. In Fig. 5, no breakdown potential is observed for the $\mathrm{Mg}$. $E_{\mathrm{b}}$ for APTMS/Mg was $-1320 \mathrm{mV}$ and the $E_{\mathrm{b}}$ dramatically decreases to below $-1040 \mathrm{mV}$ after the immobilization of AgNPs. These results implied that AgNPs/APTMS coatings were more corrosion resistant than the APTMS film ${ }^{[39]}$.

Table 1 Electrochemical parameters of the polarization curves

\begin{tabular}{cccc}
\hline Sample & $\begin{array}{c}E_{\text {corr }} \\
(\mathrm{mV})\end{array}$ & $\begin{array}{c}i_{\text {corr }} \\
\left(\mathrm{A} / \mathrm{cm}^{2}\right)\end{array}$ & $\begin{array}{c}E_{\mathrm{b}} \\
(\mathrm{mV})\end{array}$ \\
\hline $\mathrm{Mg}$ & -1580 & $3.42 \times 10^{-5}$ & \\
APTMS/Mg & -1550 & $6.06 \times 10^{-6}$ & -1320 \\
AgNPs/APTMS/Mg & -1390 & $5.87 \times 10^{-6}$ & -1040 \\
\hline
\end{tabular}




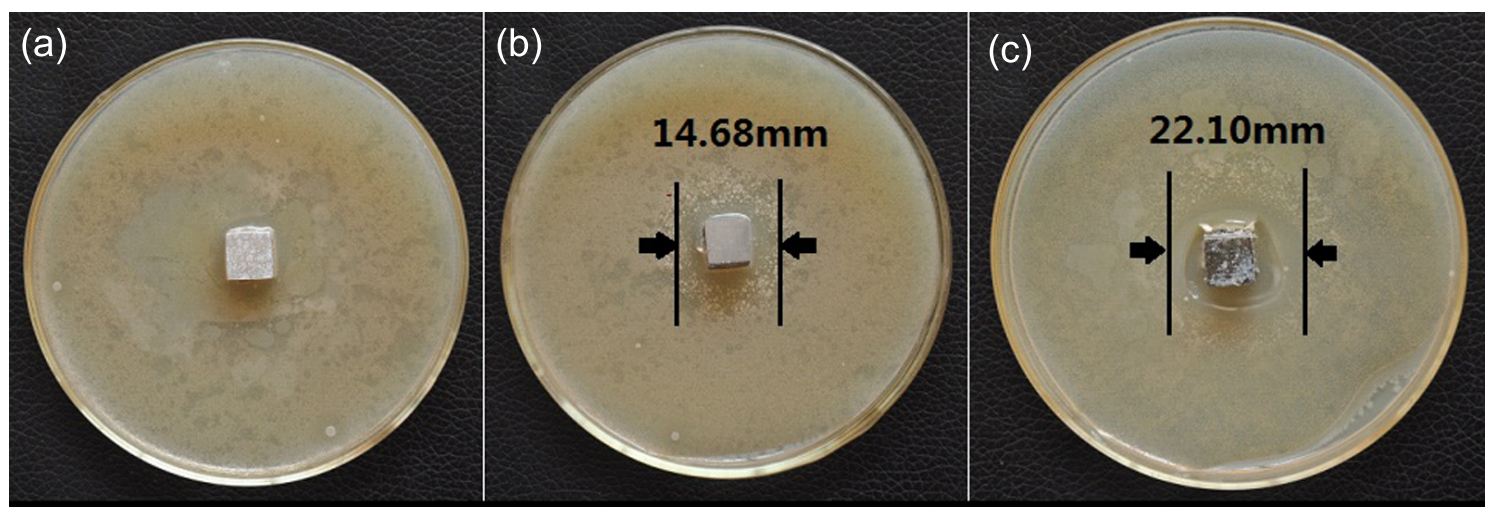

Fig. 6 Photographic images of the zone of inhibition of Mg (a), APTMS/Mg (b) and AgNPs/APTMS/Mg (c) samples

\subsection{Antibacterial activity}

The antibacterial activity of $\mathrm{Mg}$, APTMS/Mg and AgNPs/APTMS/Mg substrates were assessed against Escherichia coli incubated on agar plates for $24 \mathrm{~h}$ at $37^{\circ} \mathrm{C}$. As shown in Fig. 6, the diameters of inhibition zones of the treated samples (Fig. 6(b) and (c)) were $14.86 \mathrm{~mm}$ and $22.10 \mathrm{~mm}$, respectively, whereas no inhibition zone was observed in the control sample (Fig. 6(a)). The results show that both APTMS/Mg and AgNPs/APTMS/Mg have an ability to inhibit the growth of Escherichia coli. It was reported that the amino groups of APTMS could act as bactericides by inducing phase separation of charged and uncharged lipids inside the cytoplasma membrane of bacteria and causes the death of the microorganism ${ }^{[40]}$. Notably, AgNPs/APTMS/Mg has a higher bactericidal efficiency, which was attributed to the antibacterial performance of both the APTMS and the immobilized AgNPs.

\section{Conclusions}

AgNPs were chemically assembled on the AZ31 alloy by the coupling agent, APTMS. APTMS is connected to AZ31 by the $\mathrm{Si}-\mathrm{O}-\mathrm{Mg}$ band and AgNPs could be connected to APTMS by electrostatic inter-attraction between negatively charged AgNPs and partially protonated amino groups. The APTMS film and the hybrid AgNPs/APTMS coating improve the corrosion resistance of the AZ31 alloy. Both of the modified substrates have obvious bactericidal efficiency against Escherichia coli. The AgNPs/APTMS/Mg has higher bactericidal efficiency than the APTMS/Mg substrate.

\section{Acknowledgements}

This work was supported by National Natural Science Foundation of China (No. 51241001), NSF of Shandong Province (No. ZR2011EMM004), the open foundation of State Key Laboratory for Corrosion and Protection (No.
SKLCP21012KF03), Taishan Scholarship Project of Shandong Province (No. TS20110828) and the Basic Research Project of Qingdao Science and Technology Program (No. 13-1-4-171-jch).

\section{REFERENCES}

[1] D. Tie, F. Feyerabend, W.D. Müller, R. Schade, K. Liefeith, K.U. Kainer and R. Willumeit, Eur. Cell. Mater. 25 (2013) 284.

[2] J.H. Tian, Y.P. Jiao, C.R. Zhou, X.L. Dang, S. Ding, L.H. Li and H. Li, Chin. J. Mater. Res. 26 (2012) 449. (in Chinese)

[3] J.H. Tian, S. Ding, C.R. Zhou, L.H. Li, P. Zhang, Y.P. Jiao and H. Li, J. Funct. Mater. 44 (2013) 640.

[4] J. Chen, J.H. Dong, J.Q. Wang, E.H. Han and W. Ke, Corros. Sci. 50 (2008) 3610.

[5] T.F. de Conceicao, N. Scharnagl, C. Blawert, W. Dietzel and K.U. Kainer, Thin Solid Films 518 (2010) 5209.

[6] R.C. Zeng, Z.D. Lan, L.H. Kong,Y.D. Huang and H.Z. Cui, Surf. Coat. Technol. 205 (2011) 3347.

[7] R.C. Zeng, Z.D. Lan, J. Chen, X.H. Mo and E.H. Han, Chin. J. Nonferrous Met. 19 (2009) 397. (in Chinese)

[8] R.C. Zeng, J. Chen, J. Kuang, J. Zhang and Y. Wang, Rare Met. 29 (2010) 193.

[9] M. Oki and E. Charles, Mater. Lett. 63 (2009) 1990.

[10] H. Takahashi, N. Shirahata, T. Narushima and T. Yonezawa, Appl. Surf. Sci. 262 (2012) 129.

[11] J.H. An, W.A. El-Said, C.H. Yea, T.H. Kim and J.W. Choi, J. Nanosci. Nanotechnol. 11 (2011) 4424.

[12] Y.Y. Yue, Z.X. Liu, T.T. Wan and P.C. Wang, Prog. Org. Coat. 76 (2013) 835.

[13] L. Calabrese, L. Bonaccorsi and E. Proverbio. J. Coat. Technol. Res. 9 (2012) 597.

[14] L. Li and Q.B. Wang, ACS Nano 7 (2013) 3053.

[15] M. Asbahi, H. Duan, K.T. Lim, V. Ng, N. Thiyagarajah, F. Wang and J.K. Yang, Langmuir 28 (2012) 16782.

[16] A.M. Yousefi, Y.L. Zhou, A. Querejeta-Fernández, K. Sun and N.A. Kotov, J. Phys. Chem. Lett. 3 (2012) 3249 .

[17] A.V. Fuchs, S. Ritz, S. Pütz, V. Mailänder, K. Landfester and U. Ziener, Biomater. Sci. 1 (2013) 470. 
[18] V. Kumar, C. Jolivalt, J. Pulpytel, R. Jafari and F. Arefi-Khonsari, J. Biomed. Mater. Res. A 101 (2013) 1121.

[19] V. Gopinath, S. Priyadarshini, N. Meera Priyadharsshini, K. Pandian and P. Velusamy, Mater. Lett. 91 (2013) 224.

[20] N. Fukuda, N. Ishida, K. Nomura, T. Wang, K. Tamada and H. Ushijima, Langmuir 27 (2011) 12916.

[21] N.R. Jana, L. Gearheart and C.J. Murphy, Chem. Commun. 7 (2001) 617.

[22] A.F. Wang, H.Y. Tang, T. Cao, S.O. Salley, K.Y. Simon Ng., J. Colloid Interface Sci. 291 (2005) 438.

[23] L.M. Chen, L. Zheng, Y.H. Lv, H. Liu, G.C. Wang, N. Ren, D. Liu, J.Y. Wang and R.I. Boughton, Surf. Coat. Technol. 204 (2010) 3871.

[24] R.H. Tian, T.N. Rao, Y. Einaga and J.F. Zhi, Chem. Mater. 18 (2006) 939.

[25] A.S. Dehnavi, A. Aroujalian, A. Raisi and S. Fazel, J. Appl. Polym. Sci. 127 (2) (2013) 1180.

[26] D.V. Quang, P.B. Sarawade, A. Hilonga, J.K. Kim, Y.G. Chai, S.H. Kim, J.Y. Ryu and H.T. Kim, Colloids Surf. A: Physicochem. Eng. Asp. 389 (2011) 118.

[27] A.F. Scott, J.E. Gray-Munro and J.L. Shepherd, J. Colloid Interface Sci. 343 (2010) 474.
[28] Q. Chen and N.L. Yakovlev, Appl. Surf. Sci. 257 (2010) 1395.

[29] F. Zucchi, A. Frignani, V. Grassi, A Balbo and G. Trabaelli, Mater. Chem. Phys. 110 (2008) 263.

[30] W.J. van Ooij and D. Zhu, Corrosion 57 (2001) 413.

[31] E. Ukaji, T. Furusawa, M. Sato and N. Suzuki, Appl. Surf. Sci. 254 (2007) 563.

[32] J.Y. Hu, Q. Li, X.K. Zhong, L.Q. Li and L. Zhang, Thin Solid Films 519 (2010) 1361.

[33] B.C. Wang, Corrosion and Protection of Materials, Peking University Press, Beijing, 2012, p. 64. (in Chinese)

[34] Y. Okazaki, Y. Ito, K. Kyo and T. Tateishi, Mater. Sci. Eng. A 213 (1996) 138.

[35] Y. Wang, J. Xiong, J. Yan, H. Fan and J. Wang, Surf. Coat. Technol. 206 (2011) 1277.

[36] X.Y.Lu, Y. Zuo, X.H. Zhao and Y.M. Tang, Corros. Sci. 60 (2012) 165.

[37] H. Zhao and J.Z. Cui, Surf. Coat. Technol. 201 (2007) 4512.

[38] Y.C. Xin, C.L. Liu, K.F. Huo, G.Y Tang, X.B. Tian and P.K. Chu, Surf. Coat. Technol. 203 (2009) 2554.

[39] M.E. Wilms, V.J. Gadgil, J.M. Krougman and F.P. Ijsseling, Corros. Sci. 36 (1994) 871.

[40] J. Song, H. Kang, C. Lee, S.H. Hwang and J. Jang, Appl. Mater. Interfaces 4 (2012) 460. 